\title{
Incident vertebral fractures 12 months following glucocorticoid initiation in children with rheumatic disorders
}

\author{
Bianca A Lang ${ }^{1 *}$, Celia Rodd ${ }^{2}$, Timothy Ramsay ${ }^{10}$, David A Cabral ${ }^{7}$, Peter B Dent ${ }^{3}$, Janet E Ellsworth ${ }^{6}$, \\ Kristin M Houghton ${ }^{7}$, Adam Huber ${ }^{1}$, Roman Jurencak ${ }^{10}$, Maggie Larché ${ }^{3}$, Claire MA LeBlanc ${ }^{6}$, Brian Lentle ${ }^{7}$, \\ MaryAnn Matzinger ${ }^{10}$, Paivi M Miettunen ${ }^{8}$, Kiem Oen ${ }^{9}$, Johannes Roth ${ }^{10}$, Claire Saint-Cyr ${ }^{5}$, Rosie Scuccimarri ${ }^{2}$, \\ Nazih Shenouda ${ }^{10}$, Leanne M Ward ${ }^{10}$, Canadian STOPP Consortium ${ }^{4}$
}

From 2011 Pediatric Rheumatology Symposium sponsored by the American College of Rheumatology Miami, FL, USA. 2-5 June 2011

\section{Purpose}

Compromised bone health is recognized as an important source of morbidity among children with glucocorticoid (GC)-treated rheumatic diseases (RD). The aims of this study were to determine the frequency and characteristics of incident vertebral fractures (VF) 12 months after GC initiation in a prospectively-followed cohort of children with RD, and to examine clinical factors associated with their development.

\begin{abstract}
Methods
Children ( $<17$ years) initiating GC for treatment of RD between January 2005 and December 2007 in ten participating Canadian tertiary pediatric centers were enrolled in the Steroid-Associated Osteoporosis in the Pediatric Population (STOPP) study. Enrolled patients had baseline (within 30 days of initiating GC) and 6- monthly spine areal (a) BMD studies. Additionally, radiographs of the thoracolumbar spine at baseline and 12 months $(\mathrm{m})$ were evaluated using the Genant semi-quantitative method. Fractures present at baseline (prevalent VFs) were documented. An incident VF was defined as a new VF or worsening of an existing fracture. Patients also had baseline and 3 monthly assessment of GC exposure, clinical status including disease activity (measured on a $10 \mathrm{~cm}$ visual analogue scale by the patient's rheumatologist), and questionnaires to determine physical activity and vitamin D/ calcium intake.
\end{abstract}

'Dalhousie University, Halifax, NS, Canada

Full list of author information is available at the end of the article

\section{Results}

Of 135 patients enrolled, data were available on 118 (64\% female, median age 10.8 years) at $12 \mathrm{~m}$. Diagnoses included juvenile dermatomyositis (JDM) (23\%), juvenile idiopathic arthritis (JIA) (36\%), systemic lupus (SLE) and related conditions (18\%), systemic vasculitis (14\%), and other (9\%). At $12 \mathrm{~m}, 7$ patients (6\%) had 12 incident VFs (3 SLE, 2 JDM, 1 vasculitis, 1 overlap). All incident VFs were new fractures; 5 patients had a single VF, one had 2 VFs and one had 5 VFs. Three patients had mild and 4 had moderate VFs. Nine (75\%) of the incident VFs were thoracic and 11 (92\%) had wedge morphology. Patients with and without incident VFs were similar for age, gender, pubertal status, disease activity, physical activity, vitamin $\mathrm{D} /$ calcium intake and presence of back pain. The decrease in spine aBMD and increase in BMI in the first 6 months was larger in those with incident VFs $(\Delta$ spine aBMD Z-score mean -0.8, SD 0.4; $\Delta$ BMI Z-score +1.7, SD 1.0) versus those without $(\Delta$ spine aBMD Z-score -0.4, SD 0.5; $\Delta$ BMI Z-score +0.5 SD 0.8). Cumulative $\mathrm{GC}$ dose $\left(\mathrm{g} / \mathrm{m}^{2}\right)$ was almost double in those with incident VFs (median $9.3 \mathrm{~g} / \mathrm{m}^{2}$, range 3.0-12.5) versus those without (median 5.4, range 0.01-27.5); with the greatest difference in GC dose seen within the first $6 \mathrm{~m}$. None of the 9 children with baseline prevalent VFs had incident fractures. In 8 of these 9 patients, spine status had improved overall at $12 \mathrm{~m}$.

\section{Conclusion}

Incident VFs occurred in a small proportion of our cohort (6\%); however one patient was more severely 
affected. Children with incident VFs received almost twice as much GC therapy as those without, had a greater decline in spine BMD, and manifested greater increases in BMI. Back pain and baseline prevalent VFs did not appear to be associated with incident VFs. Funded by CIHR.

\section{Disclosure}

Bianca A. Lang: None; Celia Rodd: None; Timothy Ramsay: None; David A. Cabral: None; Peter B. Dent: Roche , 6; Janet E. Ellsworth: None; Kristin M. Houghton: None; Adam Huber: None; Roman Jurencak: None; Maggie Larché: None; Claire M.A. LeBlanc: None; Brian Lentle: None; MaryAnn Matzinger: None; Paivi M. Miettunen: None; Kiem Oen: None; Johannes Roth: None; Claire Saint-Cyr: None; Rosie Scuccimarri: None; Nazih Shenouda: None; Leanne M. Ward: None; and the Canadian STOPP Consortium: None.

\section{Author details}

${ }^{1}$ Dalhousie University, Halifax, NS, Canada. ${ }^{2}$ McGill University, Montreal, QC, Canada. ${ }^{3}$ McMaster University, Hamilton, ON, Canada. ${ }^{4}$ National Pediatric Bone Health Working Group, Ottawa, ON, Canada. ${ }^{5}$ Université de Montréal, Montreal, QC, Canada. ' University of Alberta, Edmonton, AB, Canada.

${ }^{7}$ University of British Columbia, Vancouver, BC, Canada. ${ }^{8}$ University of Calgary, Calgary, AB, Canada. ${ }^{9}$ University of Manitoba, Winnipeg, MB, Canada.

${ }^{10}$ University of Ottawa, Ottawa, ON, Canada.
doi:10.1186/1546-0096-10-S1-A75

Cite this article as: Lang et al:: Incident vertebral fractures 12 months following glucocorticoid initiation in children with rheumatic disorders. Pediatric Rheumatology 2012 10(Suppl 1):A75.
Submit your next manuscript to BioMed Central and take full advantage of:

- Convenient online submission

- Thorough peer review

- No space constraints or color figure charges

- Immediate publication on acceptance

- Inclusion in PubMed, CAS, Scopus and Google Scholar

- Research which is freely available for redistribution

Submit your manuscript at www.biomedcentral.com/submit 